\title{
Social Studies of Science
}

http://sss.sagepub.com

\section{Things Fall Apart: Disaster, Infrastructure, and Risk}

Benjamin Sims

Social Studies of Science 2007; 37; 93

DOI: $10.1177 / 0306312706069429$

The online version of this article can be found at:

http://sss.sagepub.com

\author{
Published by: \\ (5)SAGE Publications \\ http://www.sagepublications.com
}

Additional services and information for Social Studies of Science can be found at:

Email Alerts: http://sss.sagepub.com/cgi/alerts

Subscriptions: http://sss.sagepub.com/subscriptions

Reprints: http://www.sagepub.com/journalsReprints.nav

Permissions: http://www.sagepub.com/journalsPermissions.nav 


\section{$S \mid S S$}

\section{Things Fall Apart}

\section{Disaster, Infrastructure, and Risk}

\section{Benjamin Sims}

Keywords disasters, infrastructure, order, risk

Turning and turning in the widening gyre

The falcon cannot hear the falconer;

Things fall apart; the centre cannot hold;

Mere anarchy is loosed upon the world,

The blood-dimmed tide is loosed, and everywhere

The ceremony of innocence is drowned ...

(William Butler Yeats, excerpted from The Second Coming)

Watching the tragedy that was Hurricane Katrina unfold along the US Gulf Coast was a profoundly disturbing experience. Although in retrospect the failures we saw appear to have been almost inevitable, initially they seemed practically inconceivable. The disaster evoked very visceral feelings - shock, disgust, sadness, anger. Why should an event like Katrina have such emotional resonance? Such reactions often implicate a perceived threat to deeply held beliefs about material, moral, or social order (Douglas, 1966). Rumors, media accounts, and official reports of death, mayhem, and squalor in New Orleans - exaggerated though many of them turned out to be - expressed a profound sense that taken-for-granted assumptions were falling apart.

Hurricane Katrina deflated assumptions about the ability of a wealthy, technologically advanced society to handle a natural disaster of terrible, but not necessarily cataclysmic, proportions. This has given a certain sociotechnical flavor to the controversies that emerged in the wake of the storm: in media coverage, as well as in the political arena, the dependencies between technological systems and social institutions have been a significant focus of attention. Since I believed that science and technology studies ought to be able to offer some useful insight into the nature of these interdependencies, 
I organized a discussion session on Katrina at the 2005 Annual Meeting of the Society for Social Studies of Science in Pasadena, California, in which six of eight authors represented in this comment section participated. The discussion converged upon issues of infrastructure and risk, and it raised enough points of mutual interest that it seemed worth following up with published commentaries. I would like to thank the participants and the audience members present at the $4 \mathrm{~S}$ session for stimulating a very productive dialogue.

Natural and technological disasters, like scientific controversies, are a useful theme for science and technology studies, because they open up for examination (sometimes quite literally) networks of social and material relations that appear settled. They provide fertile ground to perform what Geoff Bowker has called 'infrastructural inversion': bringing to the foreground the central importance of technologies, people and work practices that ordinarily reside in the background (Bowker, 1994: 10-14). In different ways, the essays in this section on the hurricane and its aftermath execute this kind of inversion.

Infrastructure is a relational concept: it refers to something that enables something else (Star \& Ruhleder, 1996) - most often a technology that enables some human activity, but it can just as well refer to organizational forms or intellectual tools that enable technology to work. Some of the elements of infrastructure discussed in these essays are commonly understood as such - for example, levees and dikes, communications systems, sewers, landfills, roads, automobiles, gasoline supply networks, and petrochemical plants. Others are less obvious, but equally significant, elements of infrastructure: water boards and levee districts, bureaucratic rules, flood hazard maps, official documents, ammunition, and homes. In line with the variety of such elements, our commentaries are heterogeneous, covering everything from the historical roots of levee design to the likely outcome of official inquiries into Hurricane Katrina.

Risk to infrastructure is likely to remain a topic of increasing interest to scholars, engineers, and policymakers alike. We live in a world in which daily life is ever more tightly tied to widely distributed and multilayered infrastructure systems; a world in which technological infrastructure itself contributes to potentially enormous changes in the natural world, in which increasing population density in many areas contributes to natural disasters, and in which militaries and terrorist groups alike are increasingly interested in exploiting infrastructural vulnerabilities. The comments gathered here signal the rich set of resources that science and technology studies is poised to bring to the table in discussions not only about Hurricane Katrina, but about problems of infrastructure and risk in general.

\section{References}

Bowker, Geoffrey C. (1994) Science on the Run: Information Management and Industrial Geophysics at Schlumberger, 1920-1940 (Cambridge, MA: MIT Press).

Douglas, Mary (1966) Purity and Danger: An Analysis of Concepts of Pollution and Taboo (London: Routledge \& Kegan Paul).

Star, Susan Leigh \& Karen Ruhleder (1996) 'Steps Toward an Ecology of Infrastructure: Design and Access for Large Information Spaces', Information Systems Research $7(1): 111-34$. 
Benjamin Sims is a sociologist with the Systems Ethnography and Qualitative Modeling Team in the Statistical Sciences Group at Los Alamos National Laboratory. His research has focused on laboratories, knowledge, infrastructure, and risk. His paper, 'Safe Science: Material and Social Order in Laboratory Work,' appeared in Social Studies of Science in June 2005. Currently, he contributes to risk assessment and modeling of complex systems, and is studying patterns of knowledge and interaction in nuclear weapons work.

Address: Statistical Sciences Group, Los Alamos National Laboratory, MS F600, Los Alamos, NM 87545, USA; email bsims@lanl.gov 